IZA DP No. 9451

Hukou Changes and Subjective Well-Being

Massimiliano Tani

October 2015 


\title{
Hukou Changes and Subjective Well-Being
}

\author{
Massimiliano Tani \\ University of New South Wales \\ and IZA
}

\section{Discussion Paper No. 9451 October 2015}

\author{
IZA \\ P.O. Box 7240 \\ 53072 Bonn \\ Germany \\ Phone: +49-228-3894-0 \\ Fax: +49-228-3894-180 \\ E-mail: iza@iza.org
}

\begin{abstract}
Any opinions expressed here are those of the author(s) and not those of IZA. Research published in this series may include views on policy, but the institute itself takes no institutional policy positions. The IZA research network is committed to the IZA Guiding Principles of Research Integrity.

The Institute for the Study of Labor (IZA) in Bonn is a local and virtual international research center and a place of communication between science, politics and business. IZA is an independent nonprofit organization supported by Deutsche Post Foundation. The center is associated with the University of Bonn and offers a stimulating research environment through its international network, workshops and conferences, data service, project support, research visits and doctoral program. IZA engages in (i) original and internationally competitive research in all fields of labor economics, (ii) development of policy concepts, and (iii) dissemination of research results and concepts to the interested public.
\end{abstract}

IZA Discussion Papers often represent preliminary work and are circulated to encourage discussion. Citation of such a paper should account for its provisional character. A revised version may be available directly from the author. 


\section{ABSTRACT}

\section{Hukou Changes and Subjective Well-Being*}

The literature on subjective well-being has highlighted the negative effects associated with the restrictions and inequality imposed by the hukou system on China's rural population. However, quantifying the cost of holding a rural hukou has generally been problematic, principally for lack of suitable data or measurements. Thanks to RUMiC, a new longitudinal database on China, this limitation can be overcome by exploiting exogenous changes in hukou status due to expropriation. The results support that granting an urban hukou substantially enhances subjective well-being within the household, especially for the household heads. The results complement a growing literature on subjective well-being focusing on China.

JEL Classification: D19, H13, I31, J61, R20

Keywords: $\quad$ subjective well-being, expropriation, China

Corresponding author:

Massimiliano Tani

Institute for the Study of Labor (IZA)

Schaumburg-Lippe-Strasse 5-9

53113 Bonn

Germany

E-mail: tani@iza.org

\footnotetext{
* The Longitudinal Survey on Rural Urban Migration in China (RUMiC) consists of three components: the Urban Household Survey, the Rural Household Survey and Migrant Household Survey. It was initiated by a group of researchers at the Australian National University, the University of Queensland and the Beijing Normal University. The survey has been supported by the Chinese Foundation of Social Sciences and the Institute for the Study of Labor (IZA), which also developed and provides the Scientific Use Files (see Akgüç et al., 2014).
} 


\section{Introduction}

Since the late 1950s, the mobility of the Chinese population between rural and urban areas has been shaped by a strict household registration (hukou) system. This system registers each person at a specific location and defines an individual's household type (Goodkind and West 2002). Individuals have rural-hukou if their household registrations are in rural areas, while they have urban-hukou if they live in cities. Although people are free to move across the country, the cost of migration is substantial as rural-urban migrants have no access to the public goods of the city where they live, or can do so only at inflated prices. This includes unemployment insurance, medical and pension benefits, subsidised housing and local schooling for their children (Chan, 2008; Cai, Park and Zhao, 2009; Frijters, Lee and Meng, 2010). It is hence common to find that migrants have worse labour market outcomes than their urban hukou-holders counterparts (OECD, 2011; Meng, 2012) and worse health status (Zhang and Kanbur, 2005).

While at present no discussion is in place about removing the hukou system, the Chinese Government has undertaken a number of initiatives to target the inequality associated with it. For example certain rights such as subsidies to food and staples for those living in cities have been eliminated (1992), and changes have been introduced to grant urban residence to investors or those making a substantial purchase of real estate (1999 and 2001). Restrictions to urban hukou in relatively small cities in some parts of China have also eased (Lin and Ho, 2003). Yet, to date the hukou system remains a key institutional barrier creating segregation in the labour market and in the society (Zhao 2004, Chan and Zhang 1999).

One of the main challenges faced by the literature in analysing the costs of the hukou system is the general lack of data on the few circumstances where the residence status of an individual changes, as it occurs when one (typically a military or party manager) is relocated for work to a city, or moves for studying at university. As a result existing estimates on the costs of hukou 
based on survey data tend to use instrumental variables.

This paper provides a new estimate of the cost of the hukou system on individual utility using an exogenous shock to hukou status (expropriation with a change in legal rights), which is captured by the Longitudinal Survey on Rural Urban Migration in China (RUMiC). Since residence status in China was effectively fixed in the late 1950s, whilst expropriation reported in the RUMiC occurs mostly in the late 1990s and early 2000s, this shock can be viewed as orthogonal to individual locational choices.

The SWB index used as dependent variable is constructed from a General Health Questionnaire of 12 questions covering a respondent's feelings and outlook on life (GHQ-12). The GHQ-12 is commonly used in analyses of mental disorders and general psychiatric wellbeing (Clark and Oswald, 1994, 2002).

The results support that a change in legal rights due to expropriation positively and significantly affects an individual's SWB. The enhancement is in the order of $3 \%$ based on the average GHQ12 of those surveyed in RUMiC. This result is robust to several empirical specifications.

The remainder of the paper is organized as follows: Section 2 provides a short summary of the relevant literature. Section 3 describes the data. Section 4 discusses the methodology. Section 5 presents the results. Section 6 concludes.

\section{Literature}

A growing recent literature has highlighted the value of SWB measures to complement traditional analyses focusing solely on observable economic outcomes such as employment or income. SWB adds a psychological dimension to economic outcome measures, and this is particularly relevant in welfare analyses of specific policies (e.g. tax on cigarettes) or outcomes related to health, innovation, and productivity for which how an individual feels may play a significant role. The research activity on SWB has proceeded in parallel with the publication of 
institutional reports on happiness across countries (Sachs et al, 2012; Helliwell et al, 2013) and of best practices for data collection (OECD, 2013), which have been adopted in several developed and developing countries, further contributing to new data sources and research. SWB is normally seen as a proxy for experienced utility (Kahneman and Sugden, 2005; Krueger and Schkade, 2008), and this characteristic adds to its relevance in analyses of economies in transition where the quality of human life and life satisfaction are often inextricably related to fundamental decisions about policy regimes and mechanisms of resource allocation.

In general SWB is positively and strongly influenced by socio-economic status and perceived health status, though the positive link between economic and subjective wellbeing is stronger in countries with low average incomes. In the case of China, a number of studies have used SWB to explore its measurement and determinants (Chen and Davey, 2008), or the relationship between life satisfaction and outcomes as different as health (Knight and Song, 2006; Appleton and Song, 2008; Liang and Wang, 2013), occupational mobility (Liang and Zhu, 2014; Liang and Lu, 2014), and housing (Hu, 2013; Cheng, Smyth and Wang, 2013) amongst others.

Some authors have related SWB to the hukou system, and the inequality associated with it. For example, Demurger, $\mathrm{Li}$ and $\mathrm{Xu}$ (2014) build on the fact that the hukou status separates families between those migrating for work and those left behind, and find that constrained family living arrangements lower migrants' happiness, especially in the case of parents separated from their child. Jiang, Lu and Sato (2012) find that the hukou identity of an individual negatively affects happiness, regardless of whether people are urban residents or rural-urban migrants. Chen (2013) finds that rural-to-urban migrants' education and occupation are significantly related to the level of perceived institutional discrimination. These studies however identify the effect of the hukou system either through some kind of instrument (Demurger, Li and $\mathrm{Xu}$ ) or using subjective responses to questionnaires (Jiang, Lu and Sato; Chen).

The contribution of this paper is the identification of a change in hukou status through a specific response asking the reasons behind an individual's change in hukou status. Expropriation does 
not automatically lead to a change in hukou status, and there is no certainty that the population at risk of possible expropriation may know in advance about the possibility of getting an urban hukou if that event occurred. Even in that case, the strict regime of household registration dating since 1958 would be a formidable barrier to enable one to relocate his/her residence to where the land is likely to be expropriated. The institutional setting characterising expropriation as well as the analysis of its effects on labour market outcomes and education have been discussed by Akguec, Liu and Tani (2014), to which this paper directly relates. By exploiting what may be considered a quasi-natural experiment, it is possible to give a causal interpretation to the results.

The paper hence complements the large literature documenting the costs of the current hukou system in terms of labour market outcomes (Chan, 2008; Cai, Fang and Zhao, 2009; Frijters, Lee and Meng, 2010), health (Zhang and Kanbur, 2005), fertility (Liang, Yi, Sun, 2014), consumption (Chen, Lu, and Zhong, 2012), intergenerational educational attainment (Robertson and Xu, 2008; Wu, 2011; Biavaschi, Giulietti and Zimmermann, 2015), student performance amongst Chinese students in the United States (Afidi, Li and Ren, 2015).

\section{Data}

The analysis is based on data extracted from the RUMiC database (see Akgüç et al. 2014). This is a large-scale longitudinal household survey that covers individuals from around 8,000 households in rural areas (Rural Household Survey - RUMiC-RHS), around 5,000 households from urban areas (Urban Household Survey - RUMiC-UHS) and around 5,000 households of temporary migrants working in cities (Migrant Household Survey - RUMiC-MHS). Each of the three surveys includes comprehensive information on household and personal characteristics, detailed health status, employment, income, training and education of adults and children, social networks, family and social relationships, life events, and mental health measures of the individuals. The RUMiC-MHS additionally includes questions related to 
migration history. Data from the RUMiC database is publicly available for the years 2008 and 2009.

Attention is restricted to the 2008 and 2009 rural questionnaires of the RUMiC-RHS, principally as it contains information on relative income of respondents vis-à-vis the village or town where they live. It has been repeatedly found that the welfare of an individual depends on both his/her income as well as that of his/her reference group, reflecting feelings associated with status, like envy (Clark et al., 2008), though in the case of China, as well as other developing countries, the reported effect is smaller (Appleton and Song, 2008; Knight et al., 2009; Akay et al., 2012), perhaps in response to altruistic feelings towards the local community. The RUMiC-RHS also contains information on SWB collected through the 12 questions forming the GHQ-12 index, which were asked to household members present at the time of the interview. The list of questions is reported in the Appendix. The GHQ-12 is commonly used as an instrument to identify mental disorders and psychiatric wellbeing (Clark and Oswald, 1994). An equal number of questions are phrased positively and negatively, respectively. Answers reflect a 4-point Likert scale with the lower numbers indicating better feelings and a positive psychological outlook and higher numbers indicating worse feelings and a negative outlook. After adding up each of the 12 answers one gets a 48-point outlook indicator, which can be then inverted to produce an index varying between 0 for negative psychological outlook and 48 for positive psychological outlook, respectively. This index is used as dependent variable in the analysis discussed.

The RUMiC-RHS and RUMiC-UHS questionnaires also include questions on whether a respondent has changed hukou status and if so why. These questions are used to identify the treated group as those experiencing land expropriation and change in legal rights. Only $15 \%$ of all expropriated are drawn from the rural sample, RUMiC-RHS, on which this paper focuses. Table 1 summarises the main variables used in the analysis, by hukou status. The sample contains 20,275 individuals from rural households. Of these, 549 experienced expropriation 
with a change in hukou (about 3\%). The control group contains 19,726 individuals. These figures count household heads, their spouses and children.

Both samples are almost totally composed of families, as $99 \%$ of respondents are married and had children, though children only make up a small proportion of the respondents $(6 \%$ in the treated group and $4 \%$ in the control, respectively). Household heads account for about half of the respondents ( $45 \%$ versus $54 \%$ ), with their spouses accounting for the remaining share $(48 \%$ versus $42 \%)$. The average age is relatively high (47.4 years versus 49 years). The treated group has a higher average level of education, with $24 \%$ of the sample having completed senior high school or more vis-à-vis $14 \%$ in the control group.

Treated and control groups are fairly similar with respect to their physical characteristics, health and disability, and income position relative to the village or town where they live. With respect to this variable, about $60 \%$ of respondents claim to have an income similar to that of their village or town, with the remaining $40 \%$ equally split between those reporting incomes above or below the village or town average.

With reference to the dependent variable, the unconditional means shows that the GHQ-12 is slightly higher for those who have been expropriated and received an urban hukou: 29.3 versus 28.0, a difference that is statistically significant based on the Kruskal-Wallis test of equality of means.

\section{Empirical strategy}

To analyse the relationship between SWB and the change in hukou status, the following microeconometric model is used:

$$
\mathrm{SWB}_{i t}=\alpha_{0}+X_{i t} \alpha_{1}+E X P_{i} \alpha_{2}+\alpha_{3} t+F E_{i} \alpha_{4}+u_{i}+v_{i t}
$$

where SWB is the GHQ-12 indicator for individual $i$.

$X_{i}$ is a vector of individual characteristics that includes age, age square, marital status, gender, 
educational level (elementary school or lower, which is used as the reference; junior middle school and senior middle school), weight and height, whether the individual has children, health and disability (4 categories), and the individual income relative to the village (average, which is used as the reference category; below average, and above average).

$E X P_{i}$ indicates whether the hukou status of the individual has changed through expropriation. The variable $t$ is a year dummy, while $F E_{i}$ is a vector of fixed effects for the province where respondents were surveyed.

The parameters $u_{i}$ and $v_{i t}$ form the composite error term: $u_{i}$ captures time-invariant individual unobserved heterogeneity; vit is an i.i.d. component.

The parameter of interest in equation (1) is $\alpha_{2}$ as that captures the effect of the change in legal rights on an individual's SWB. This may be seen as the average cost of the hukou system on an individual's utility conditional on demographic, health and income characteristics.

The data on which to estimated equation (1) are a short panel with only two years of observations. Attrition between 2008 and 2009 in the RUMiC-RHS is below 1\% (Akguec, Giulietti and Zimmermann, 2014) limiting potential concerns of selectivity in the observations. First a regression using Ordinary Least Squares (OLS) on pooled 2008 and 2009 data is performed, with robust standard errors clustered at individual level to capture observations relating to the same individual over the two-year period. The main drawback of OLS is that the unobserved time-invariant heterogeneity is left entirely in the composite error term. This may not be problematic if that heterogeneity is uncorrelated with the observed covariates. More serious is the possibility of serial correlation in the composite error term as OLS pools data across time.

To partially eliminate the problem, equation (1) is then estimated using panel data techniques, which control the effect of time-invariant unobserved individual heterogeneity. As the covariate of interest $\left(E X P_{i}\right)$ is itself time-invariant (no expropriation with change in hukou rights occurs 
between 2008 and 2009) the analysis uses the random effects estimator. Panel estimation transforms the data by subtracting from each observation a portion $\theta$ of its time average, where $\theta$ depends on the variance of $u_{i}$ and $v_{i t}$ and the number of periods for which data are observed (Wooldridge, 2010). This quasi-demeaning of the data transforms equation (1) into: $S W B_{i t}-\theta S W B_{i}=\alpha_{0}(1-\theta)+\left(X_{i t}-\theta X_{i}\right) \alpha_{1}+\alpha_{2}(1-\theta) E X P_{i}+\alpha_{3}(1-\theta) t+F E_{i}(1-\theta) \alpha_{4}+u_{i}(1-\theta)+\left(v_{i t}-\theta v_{i}\right)$

Estimation of (2) yields consistent estimates under the assumption of orthogonality between $u_{i}$ and the observed covariates as well as of $u_{i} \sim N\left(0, \sigma_{u}^{2}\right)$ and $v_{i t} \sim N\left(0, \sigma_{v}^{2}\right)$. Although $\theta$ is not known in practice it can always be estimated (various methods are discussed in Wooldridge, 2009). An estimate of $\theta$ close to zero results in the random effect estimator being close to the pooled OLS estimator, implying that time-invariant unobserved heterogeneity is relatively unimportant since the variance of $u_{i}$ is small relative to that of vit. Conversely and more commonly, if the estimate of $\theta$ is close to 1 , then the variance of $u_{i}$ is large relative to that of $V_{i t}$, and the bias caused by unobserved time-invariant heterogeneity is large, justifying the use of panel data techniques.

To relax the assumption of orthogonality between $u_{i}$ and the observed covariates the suggested approach is to augment the random effects model with the time averaged values of the timevarying variables (Mundlak, 1978; Chamberlain, 1980; Wooldridge, 2010). This leads to adding a term $\bar{X}_{i}$ capturing the time average of $X_{i t}$ to equation (2). Adding $\bar{X}_{i}$ to the model as a control for unobserved time-invariant heterogeneity allows one to estimate the effect of changing $X_{i t}$ whilst holding the time average fixed (Wooldridge, 2010). This is the preferred specification. 


\section{Results}

Table 2 presents the results. The table is structured in such a way to reflect the three main observational groups across columns. The first group, labeled 'all household members' pools together all household members at the time of the interview, and so it includes household heads, their spouse and children when present. The second group, labeled 'household heads' presents the results obtained when the observations are restricted to household heads only. The third group, labeled 'spouses' presents the results obtained when the observations are restricted to spouses only.

Within each observational group the results are presented by estimation approach. There are hence three sets of estimates for each of the three observational groups. The first set of estimates (column labeled I) reports the results obtained using equation (1), which is estimated by pooled OLS. The second set (label II) reports the results obtained using equation (2), which applies panel random effects. The third set (label III) reports the results obtained using equation (3), which applies panel random effects with the time-averaged correction terms as suggested by Mundlak (1978).

Within each set of results the top row shows the effect of a change in legal rights due to expropriation on SWB as measured by the GHQ-12 index. The other covariates are grouped by type, so one can separately see the effects on SWB of demographic characteristics (gender, age, age square), education (junior middle school, senior middle school or higher; the reference category is elementary education or lower), affections (married, had children), health (height, weight, poor health status; the reference category is good health), and relative income (above or below the village or town average; the reference category is about the same as village or town average). All results reported in Table 2 are marginal effects. As a result they quantify the change from the average level of the GHQ-12 index of a 1-unit increase in the explanatory variable. 
The results are presented as follows. First the determinants of SWB for the whole household and using pooled OLS (model I) are discussed. This can serve as a base for comparing the results obtained here with those of the existing literature. Then I comment how the results change when unobserved time-invariant heterogeneity is controlled for under the assumption of orthogonality between the individual component and the other covariates (model II). I finally discuss the preferred estimation approach which removes the restriction on orthogonality between $u_{i}$ and $X_{i t}$ by introducing time-averaged values $X_{i}$ as correction terms (model III).

All household members. The overall statistics of the OLS estimate reported at the bottom of Table 2 suggest that model (1) explains about $20 \%$ of the variance in SWB at the household level, in line with the literature on SWB. The marginal effect reported in the first row suggests that the change in hukou status due to expropriation has a significant positive effect on the household SWB (marginal effect: .747; p-value $<.001$ ). The effect is statistically strong, and its magnitude substantial, confirming that the cost of the hukou system on rural residents is high, notwithstanding the recent reforms. Using the unconditional average household SWB of 28.04, the marginal effect of .747 implies that providing urban legal rights to a rural household can increase its SWB by about 3\%. This magnitude is similar to that associated an aboveaverage income relative to the village or town where one lives, which is another important determinant of SWB.

The results on the remaining control variables mimic those of previous work (Helliwell, 2003; Knight et al., 2009; Akay et al., 2015). As a result, being male positively affects household SWB more than being a female. Age affects SWB in a U-shape fashion. Being married is a strong and positive determinant of SWB (marginal effect: 1.862; p-value $<.001$ ), but having children is not (statistically no different from zero). Educational attainment has a strong and positive effect on SWB, as does being in good health. Poor health, albeit self-assessed, strongly reduces households' SWB. In contrast, both height and weight positively contribute to SWB, 
perhaps reflecting the general view held in China that weight is a sign of good health and prosperity.

Relative income is a strong determinant of a household's SWB, but its effect is asymmetric. Having an above-average income relative to the village or town has a strong and positive effect on SWB with a marginal effect of .689 (p-value $<.001)$. Having instead an income below the village or town average reduces SWB by more than double that amount, as the marginal effect is -1.509 ( $\mathrm{p}$-value $<.001)$. Below average earnings are associated with a much bleaker outlook for those affected, though the implications of this finding for possible subsequent related behaviour (e.g. turn it into a source of strength to overcome it or feel ashamed and limit participation in communal activities) is outside the scope of this paper.

When some control is imposed on time-invariant individual heterogeneity (model II) the results do not significantly change. The size of theta reported at the bottom of Table 2 is close to .4, an intermediate level, suggesting that the bias related to the individual effect $u_{i}$ exists but does not seem to invalidate the OLS results discussed above. The marginal effect of changing hukou status is slightly lower in the panel random effect estimation than in the pooled OLS base case, but, on average, it still raises a household's SWB by .651 points $(2.3 \%$ of the SWB average). Importantly, the statistical significance of the estimate remains strong, with a p-value of less than one percent. Signs and magnitudes of all other covariates remain close to the OLS estimates except for the marginal effects of age and age squared, which become statistically less distinguishable from zero (albeit with unchanged standard error relative to OLS).

The stability of the results discussed so far remains unaltered even when the correlation between $u_{i}$ and $X_{i t}$ is allowed (model III). The marginal effect of obtaining a city hukou following expropriation is .659 (2.3\% of the SWB average unconditional mean) with a p-value of less than one percent. No significant change arises with respect to all the other covariates, either in the sign and magnitude of the effects, or the associated standard errors relative to the pooled OLS results. 
Household head. Restricting the analysis to observations covering only the household heads does not modify the broad results of the analysis carried out at the household level. The signs of the marginal effects are identical to the ones previously discussed. Differences emerge in the magnitude of some of the effects. The effect of a change in hukou following expropriation on SWB is much stronger for the household head (pooled OLS: .938; p-value $<.001$ ), reflecting perhaps that obtaining an urban hukou does not only grant access to local public goods (in essence it is a positive income shock) but also opens a wider range of career opportunities besides agricultural work as well as better terms and conditions of employment (e.g. permanent rather than temporary contract). It is hence not surprising that the effect on SWB is higher for a male $(.948 ; \mathrm{p}$-value $<.001)$, as non-domestic work within the household is hardly evenly distributed between genders. Age instead appears to play no role in determining the household head's SWB, as its effect is practically no different from zero.

Conversely having children significantly enhances the household head's SWB: not only the marginal effect is positive and statistically significantly different from zero but its magnitude is large in both OLS and Mundlak estimates (1.175 and 2.302, respectively). As most household heads are male, this result highlights a substantial gender difference vis-à-vis having children. For males, it positively and strongly increases SWB, perhaps as this implies the ability to carry on the family name in future. For females, it has no effect on SWB.

With reference to health, weight and self-assessed health are strong determinants of SWB, in line with the results obtained by the SWB literature and those discussed at the household level. Height instead seems to have no role in determining household heads' SWB, possibly because being head of the family already gives enough status. Weight is a strong predictor of SWB amongst household heads, reflecting the common view held in China that weight underlies good fortune. 
The marginal effects of income above or below the village or town average are very close to those observed in the analysis of the household as a whole. Above-average income strongly adds to SWB while below-average income has a doubly stronger but negative effect on household heads' SWB. The similarity of the marginal effects of relative income with the analysis previously discussed is revealing that relative income in rural China is, on average, equally felt amongst household members. This underlies the relevance of income as a key relative concern in rural China, notwithstanding the substantial differences amongst the individuals underpinning the analysis.

These results are robust to model specification, when time-invariant heterogeneity is controlled (models II and III).

Spouses. The marginal effects obtained on spouses mimic in sign the results previously discussed, but generally differ in magnitude and statistical significance. The change in hukou status is half the magnitude of that obtained for the household heads, and is statistically different from zero only in the case of pooled OLS (model I), at the 10\% significance level. When timeinvariant individual unobserved heterogeneity is accounted for, the effect no longer significantly differs from zero, implying that spouses' SWB does not change with access to local public goods. One possible interpretation is that spouses, who are mostly women, do not benefit from the wider set of labour market opportunities available with an urban hukou because they remain engaged in home or farm production, unlike their husbands. Age does not appear to determine spouses' SWB, and nor does having children. In contrast, being married has a substantial positive impact on SWB, in line with what found by the SWB literature, and so does education, especially at senior middle school and above where the contribution is double that of junior middle school. It is possible that more educated women have a better understanding of the opportunities that rapid economic development in China has brought, and this translates in a more positive outlook on life. 
With reference to health, poor health has a large negative impact on SWB, similar in magnitude to that household heads. Weight has a large positive impact on SWB but only at the 5\% level of statistical significance (it was $1 \%$ in the case of household heads). At the same time, height positively contributes to spouses' SWB, though the associated marginal effect just reaches statistical significance. The contribution of height and weight, which may proxy for how one looks, appear more balanced in the case of spouses relative to household heads, perhaps reflecting the prevalence of females in the spouse group.

The effect of relative income on spouses' SWB is very close to that of the household heads. It is strongly positive in the case of above-average income relative to the village or town where the souse lives. It is strongly negative, and double in size, in the case of below-average income. The results obtained from pooled OLS regression (model I) remain unchanged once timeinvariant unobserved heterogeneity is accounted for (model II and model III), supporting the robustness of the outcomes found.

\section{Conclusions}

The literature on social wellbeing has highlighted the negative effects associated with the restrictions and inequality imposed by the hukou system on China's rural population. However, quantifying the cost of holding a rural hukou has generally been problematic, principally for lack of suitable data or measurements.

Thanks to RUMiC, a new longitudinal database on China, this limitation can be overcome by exploiting exogenous changes in hukou status due to land expropriation. The results support that a change in legal rights due to expropriation positively and significantly affects an individual's SWB, especially in the case of household heads. The enhancement is in the order of $3 \%$ based on the average GHQ-12 of those surveyed in RUMiC-RHS, and this result is robust to several specifications. This order of magnitude is similar to that of having an above-average income relative to the village or town where one lives. 
The results confirm the hukou status as a strong economic determinant of SWB in rural China, and as a source of inequality, and complement existing work on inequality in China. 
Table 1 - Characteristics of individuals in Rural estimation sample

\begin{tabular}{lcccccc}
\hline & \multicolumn{3}{c}{ Expropriated } & \multicolumn{3}{c}{ Not Expropriated } \\
Variable name & Mean & St.Dev & N & Mean & St.Dev & N \\
\hline & & & & & & \\
SWB (GHQ-12) & 29.3 & 4.92 & 549 & 28.0 & 5.02 & 19726 \\
Male & .50 & .50 & 549 & .56 & .50 & 19726 \\
Age & 47.4 & 9.4 & 549 & 49.0 & 9.0 & 19726 \\
Age2/100 & 23.4 & 9.0 & 549 & 24.9 & 8.7 & 19726 \\
Elementary of no school & .32 & .47 & 549 & .41 & .49 & 19726 \\
Junior middle school & .44 & .49 & 549 & .45 & .50 & 19726 \\
Senior middle or above & .24 & .43 & 549 & .14 & .34 & 19726 \\
Ever had children & .99 & .10 & 549 & .99 & .10 & 19726 \\
Married & .99 & .11 & 549 & .98 & .14 & 19726 \\
Height (in cm) & 164.1 & 7.2 & 549 & 164.3 & 6.6 & 19726 \\
Weight (in kg) & 62.5 & 9.7 & 549 & 60.7 & 8.5 & 19726 \\
Disable & .05 & .22 & 549 & .05 & .22 & 19726 \\
Household head & .45 & .49 & 549 & .54 & .50 & 19726 \\
Spouse to the Household head & .48 & .50 & 549 & .42 & .49 & 19726 \\
Other family member & .06 & .24 & 549 & .04 & .20 & 19726 \\
Relative income above average & .22 & .41 & 549 & .20 & .40 & 19726 \\
Relative income about average & .59 & .49 & 549 & .59 & .49 & 19726 \\
Relative income below average & .19 & .39 & 549 & .21 & .40 & 19726 \\
\hline
\end{tabular}

Source: 2008 and 2009 Rural Household Survey of RUMiC. 
Table 2 - Determinants of Subjective Well Being (SWB) - marginal effects

\begin{tabular}{|c|c|c|c|c|c|c|c|c|c|}
\hline \multirow[b]{2}{*}{ SWB (GHQ-12) } & \multicolumn{3}{|c|}{ All Household Members } & \multicolumn{3}{|c|}{ Household Heads } & \multicolumn{3}{|c|}{ Spouses } \\
\hline & $\begin{array}{c}\text { OLS } \\
\text { I }\end{array}$ & $\begin{array}{c}\text { Panel RE } \\
\text { II } \\
\end{array}$ & $\begin{array}{c}\text { Mundlak RE } \\
\text { III }\end{array}$ & $\begin{array}{c}\text { OLS } \\
\text { I }\end{array}$ & $\begin{array}{c}\text { Panel RE } \\
\text { II }\end{array}$ & $\begin{array}{c}\text { Mundlak RE } \\
\text { III }\end{array}$ & $\begin{array}{c}\text { OLS } \\
\text { I }\end{array}$ & $\begin{array}{c}\text { Panel RE } \\
\text { II } \\
\end{array}$ & $\begin{array}{c}\text { Mundlak RE } \\
\text { III }\end{array}$ \\
\hline Expropriated & $\begin{array}{c}.747 * * * \\
(.197)\end{array}$ & $\begin{array}{c}.651 * * * \\
(.222)\end{array}$ & $\begin{array}{c}.659 * * * \\
(.219)\end{array}$ & $\begin{array}{c}.938 * * * \\
(.291)\end{array}$ & $\begin{array}{l}.811 * * \\
(.332)\end{array}$ & $\begin{array}{l}.803 * * \\
(.317)\end{array}$ & $\begin{array}{l}.477 * \\
(.290)\end{array}$ & $\begin{array}{c}.414 \\
(.326)\end{array}$ & $\begin{array}{c}.429 \\
(.329)\end{array}$ \\
\hline Male & $\begin{array}{c}.773 * * * \\
(.169)\end{array}$ & $\begin{array}{c}.836^{* * *} \\
(.190)\end{array}$ & $\begin{array}{c}.787 * * * \\
(.181)\end{array}$ & $\begin{array}{c}.943 * * * \\
(.244)\end{array}$ & $\begin{array}{c}.988 * * * \\
(.280)\end{array}$ & $\begin{array}{c}.887 * * * \\
(.259)\end{array}$ & $\begin{array}{c}.434 \\
(.298)\end{array}$ & $\begin{array}{l}.515 \\
(.335)\end{array}$ & $\begin{array}{c}.470 \\
(.333)\end{array}$ \\
\hline Age & $\begin{array}{c}-.081 * * \\
(.036)\end{array}$ & $\begin{array}{l}-.071 * \\
(.040)\end{array}$ & $\begin{array}{l}-.077 * \\
(.041)\end{array}$ & $\begin{array}{l}-.092 * \\
(.056)\end{array}$ & $\begin{array}{l}-.081 \\
(.063)\end{array}$ & $\begin{array}{l}-.075 \\
(.066)\end{array}$ & $\begin{array}{l}-.082 \\
(.059)\end{array}$ & $\begin{array}{l}-.079 \\
(.066)\end{array}$ & $\begin{array}{l}-.078 \\
(.069)\end{array}$ \\
\hline Age $2 / 100$ & $\begin{array}{l}.076^{* *} \\
(.037)\end{array}$ & $\begin{array}{c}.059 \\
(.041)\end{array}$ & $\begin{array}{c}.068 \\
(.042)\end{array}$ & $\begin{array}{c}.090 \\
(.056)\end{array}$ & $\begin{array}{c}.072 \\
(.064)\end{array}$ & $\begin{array}{c}.068 \\
(.067)\end{array}$ & $\begin{array}{c}.078 \\
(.062)\end{array}$ & $\begin{array}{c}.070 \\
(.069)\end{array}$ & $\begin{array}{c}.071 \\
(.072)\end{array}$ \\
\hline Spouse & $\begin{array}{l}-.280^{*} \\
(.165)\end{array}$ & $\begin{array}{l}-.227 \\
(.187)\end{array}$ & $\begin{array}{l}-.295^{*} \\
(.178)\end{array}$ & - & - & - & - & - & - \\
\hline Child & $\begin{array}{c}.207 \\
(.191)\end{array}$ & $\begin{array}{l}.218 \\
(.210)\end{array}$ & $\begin{array}{c}.257 \\
(.211)\end{array}$ & - & - & - & - & - & - \\
\hline Up to junior middle school & $\begin{array}{c}.513 * * * \\
(.074)\end{array}$ & $\begin{array}{c}.515^{* * *} \\
(.086)\end{array}$ & $\begin{array}{c}.519 * * * \\
(.085)\end{array}$ & $\begin{array}{c}.486^{* * *} \\
(.101)\end{array}$ & $\begin{array}{c}.493 * * * \\
(.118)\end{array}$ & $\begin{array}{c}.504 * * * \\
(.115)\end{array}$ & $\begin{array}{c}.568 * * * \\
(.116)\end{array}$ & $\begin{array}{c}.558 * * * \\
(.132)\end{array}$ & $\begin{array}{c}.560 * * * \\
(.133)\end{array}$ \\
\hline Senior middle school + & $\begin{array}{c}.686^{* * *} \\
(.010)\end{array}$ & $\begin{array}{c}.707 * * * \\
(.115)\end{array}$ & $\begin{array}{c}.710 * * * \\
(.121)\end{array}$ & $\begin{array}{c}.576^{* * *} \\
(.127)\end{array}$ & $\begin{array}{c}.602 * * * \\
(.147)\end{array}$ & $\begin{array}{c}.600 * * * \\
(.151)\end{array}$ & $\begin{array}{c}.911 * * * \\
(.185)\end{array}$ & $\begin{array}{c}.890 * * * \\
(.211)\end{array}$ & $\begin{array}{c}.887 * * * \\
(.223)\end{array}$ \\
\hline Ever had children & $\begin{array}{c}.279 \\
(.335)\end{array}$ & $\begin{array}{l}-.017 \\
(.356)\end{array}$ & $\begin{array}{c}.611 \\
(.397)\end{array}$ & $\begin{array}{c}1.175^{* *} \\
(.563)\end{array}$ & $\begin{array}{c}.584 \\
(.545)\end{array}$ & $\begin{array}{c}2.302 * * \\
(.615)\end{array}$ & $\begin{array}{c}.528 \\
(.734)\end{array}$ & $\begin{array}{l}.628 \\
(.755)\end{array}$ & $\begin{array}{c}.212 \\
(.947)\end{array}$ \\
\hline Marital status & $\begin{array}{c}1.862 * * * \\
(.252)\end{array}$ & $\begin{array}{c}1.556^{* * * *} \\
(.293)\end{array}$ & $\begin{array}{c}2.020 * * * \\
(.277)\end{array}$ & $\begin{array}{c}1.862 * * * \\
(.282)\end{array}$ & $\begin{array}{c}1.535 * * * \\
(.335)\end{array}$ & $\begin{array}{c}2.076^{* * *} \\
(.306)\end{array}$ & $\begin{array}{c}1.981 * * * \\
(.770)\end{array}$ & $\begin{array}{c}1.921 * * * \\
(.720)\end{array}$ & $\begin{array}{c}2.423 * * \\
(1.032)\end{array}$ \\
\hline
\end{tabular}




\begin{tabular}{|c|c|c|c|c|c|c|c|c|c|}
\hline Height (in cm) & $\begin{array}{l}.018 * * \\
(.007)\end{array}$ & $\begin{array}{l}.019 * * \\
(.007)\end{array}$ & $\begin{array}{l}.017 * * \\
(.008)\end{array}$ & $\begin{array}{c}.014 \\
(.009)\end{array}$ & $\begin{array}{c}.015 \\
(.010)\end{array}$ & $\begin{array}{c}.010 \\
(.011)\end{array}$ & $\begin{array}{l}.021 * \\
(.011)\end{array}$ & $\begin{array}{l}.021 * \\
(.011)\end{array}$ & $\begin{array}{c}.020 \\
(.013)\end{array}$ \\
\hline Weight (in kg) & $\begin{array}{c}.016^{* * *} \\
(.005)\end{array}$ & $\begin{array}{c}.016^{* * *} \\
(.005)\end{array}$ & $\begin{array}{c}.017 * * * \\
(.006)\end{array}$ & $\begin{array}{c}.017 * * * \\
(.006)\end{array}$ & $\begin{array}{c}.018 * * * \\
(.006)\end{array}$ & $\begin{array}{c}.020 * * * \\
(.008)\end{array}$ & $\begin{array}{l}.018 * * \\
(.008)\end{array}$ & $\begin{array}{l}.018 * * \\
(.008)\end{array}$ & $\begin{array}{l}.020 * * \\
(.009)\end{array}$ \\
\hline Poor health & $\begin{array}{c}-7.351 * * * \\
(.224)\end{array}$ & $\begin{array}{c}-6.579 * * * \\
(.234)\end{array}$ & $\begin{array}{c}-6.588 * * * \\
(.163)\end{array}$ & $\begin{array}{c}-7.013 * * * \\
(.324)\end{array}$ & $\begin{array}{c}-6.302 * * * \\
(.339)\end{array}$ & $\begin{array}{c}-6.312^{* * *} \\
(.207)\end{array}$ & $\begin{array}{c}-7.762 * * * \\
(.315)\end{array}$ & $\begin{array}{c}-6.956^{* * * *} \\
(.330)\end{array}$ & $\begin{array}{c}-6.949 * * * \\
(.242)\end{array}$ \\
\hline Income higher than village & $\begin{array}{c}.689 * * * \\
(.078)\end{array}$ & $\begin{array}{c}.711 * * * \\
(.089)\end{array}$ & $\begin{array}{c}.707 * * * \\
(.095)\end{array}$ & $\begin{array}{c}.697 * * * \\
(.104)\end{array}$ & $\begin{array}{c}.705^{* * *} \\
(.121)\end{array}$ & $\begin{array}{c}.700 * * * \\
(.128)\end{array}$ & $\begin{array}{c}.659 * * * \\
(.124)\end{array}$ & $\begin{array}{c}.691 * * * \\
(.140)\end{array}$ & $\begin{array}{c}.685^{* * *} \\
(.149)\end{array}$ \\
\hline Income lower than village & $\begin{array}{c}-1.509^{* * *} \\
(.087)\end{array}$ & $\begin{array}{c}-1.575^{* * *} \\
(.356)\end{array}$ & $\begin{array}{c}-1.563 * * * \\
(.094)\end{array}$ & $\begin{array}{c}-1.477 * * * \\
(.115)\end{array}$ & $\begin{array}{c}-1.546^{* * *} \\
(.135)\end{array}$ & $\begin{array}{c}-1.524 * * * \\
(.125)\end{array}$ & $\begin{array}{c}-1.524 * * * \\
(.138)\end{array}$ & $\begin{array}{c}-1.577^{* * * *} \\
(.158)\end{array}$ & $\begin{array}{c}-1.573 * * * \\
(.148)\end{array}$ \\
\hline Constant & $\begin{array}{c}24.98 * * * \\
(1.42)\end{array}$ & $\begin{array}{c}25.04 * * * \\
(1.56)\end{array}$ & $\begin{array}{c}24.38 * * * \\
(1.63)\end{array}$ & $\begin{array}{c}24.81 * * * \\
(2.04)\end{array}$ & $\begin{array}{c}25.16^{* * *} \\
(2.29)\end{array}$ & $\begin{array}{c}23.52 * * * \\
(2.42)\end{array}$ & $\begin{array}{c}23.91 * * * \\
(2.43)\end{array}$ & $\begin{array}{c}23.79 * * * \\
(2.59)\end{array}$ & $\begin{array}{c}23.48 * * * \\
(2.81)\end{array}$ \\
\hline Province Fixed Effects & YES & YES & YES & YES & YES & YES & YES & YES & YES \\
\hline Time dummy & YES & YES & YES & YES & YES & YES & YES & YES & YES \\
\hline Observations & 20275 & 20275 & 20275 & 10911 & 10911 & 10911 & 8497 & 8497 & 8497 \\
\hline $\mathrm{R}^{2}$ overall & .2168 & .2161 & .2171 & .1980 & .1972 & .1995 & .1996 & .1988 & .1995 \\
\hline $\mathrm{R}^{2}$ within & & .0448 & .0473 & & .0456 & .0502 & & .0491 & .0507 \\
\hline $\mathrm{R}^{2}$ between & & .2473 & .2477 & & .2311 & .2324 & & .2232 & .2243 \\
\hline Theta (median) & & .395 & & & .377 & & & .409 & \\
\hline
\end{tabular}




\section{References}

Afridi, F., Li, S. X., and Ren, Y. (2015). Social identity and inequality: The impact of China's hukou system. Journal of Public Economics, 123, 17-29.

Akay, A., Bargain, O., Giulietti, C., Robalino, J. D., \& Zimmermann, K. F. (2015). Remittances and Relative Concerns in Rural China (No. 9163). IZA Discussion Papers.

Akay, A., O. Bargain, and K.F. Zimmermann (2012). Relative Concerns of Rural-to-Urban Migrants in China, Journal of Economic Behavior and Organization 81: 421-441.

Akgüç, M., C. Giulietti, and K.F. Zimmermann (2014). The RUMiC Longitudinal Survey: Fostering Research on Labor Markets in China. IZA Journal of Labor \& Development, 3:5.

Akgüç, M., X. Liu, and M. Tani (2014). Expropriation with Hukou Change: Evidence from a Quasi-Natural Experiment. (No. 8689). IZA Discussion Papers.

Appleton S. and Song L. (2008). Life satisfaction in urban China: components and determinants World Development, 36(11): 2325-2340. doi: 10.1016/j.worlddev.2008.04.009.

Biavaschi, C., C. Giulietti, and K.F. Zimmermann (2015). Sibling Influence on the Human Capital of the Left Behind, Journal of Human Capital forthcoming.

Cai, F., A. Park and YH Zhao (2009) The Chinese labor market in the Reform Era, in Brandt, Lauren and Thomas Rawski China's Great Economic Transformation: 167-214. Cambridge University Press

Chamberlain, G. (1980). Analysis of covariance with qualitative data. Review of Economic Studies, 47 (1): 225-238.

Chan, K. W. (2008). Internal Labor Migration in China: Trends, Geographical Distribution and Policies. Proceedings of the United Nations Expert Group Meeting on Population Distribution, Urbanization, Internal Migration and Development, UN/POP/EGM-URB/2008/05, United Nations: 93-122.

Chan, K. W. and Zhang, L. (1999). The hukou system and rural-urban migration in China: Processes and changes. The China Quarterly, 160: 818-855.

Chen, J. (2013). Perceived discrimination and subjective well-being among rural-to-urban migrants in China. Journal of Sociology and Social Welfare, 40:131.

Chen, Z., and Davey, G. (2008). Happiness and subjective wellbeing in mainland China. Journal of Happiness Studies, 9(4): 589-600.

Chen, B., Lu, M., and Zhong, N. (2012). Hukou and Consumption Heterogeneity: Migrants' Expenditure is Depressed by Institutional Constraints in Urban China. Available at SSRN 1989257.

Cheng, Z., King, S. P., Smyth, R. and Wang, H. (2014). Housing property rights and subjective wellbeing in urban China. Monash University. Department of Economics. Discussion Papers, 44/14: $1-23$ 
Clark, A., and A. Oswald (1994). Unhappiness and unemployment, Economic Journal 104: 648-659.

Clark, A.E., P. Frijters, and M.A. Shields (2008). Relative Income, Happiness, and Utility: An Explanation for the Easterlin Paradox and Other Puzzles, Journal of Economic Literature 46: 95-144.

Démurger, S., Li, S., \& Xu, H. (2014). Internal migration, family living arrangements and happiness in China. In IAS Program on" Human Resources and Economic Development" Seminar, Hong-Kong University of Science and Technology, Hong-Kong, 17 juillet 2013 la communication.

Frijters, P., L. Lee and X. Meng (2010). Jobs, working hours, and remuneration packages for migrants and urban residents, in X. Meng, C. Manning, S. Li and T.N. Effendi (eds.) The Great migration: rural-urban migration in China and Indonesia. Cheltenham: Edward Elgar Publishing.

Goodkind, D. and West, L. A. (2002). China's floating population: Definitions, data and recent findings. Urban Studies, 39: 2237-2250.

Helliwell, J. (2003). How's life? Combining individual and national variables to explain subjective well-being, Economic Modelling 20(2): 331-360.

Helliwell, J. F., Layard, R., and Sachs, J. (2013). World happiness report. Washington: The World Bank Group

Hu, F. (2013). Homeownership and subjective wellbeing in urban China: Does owning a house make you happier? Social Indicators Research, 110(3): 951-971.

Jiang, S., Lu, M., and Sato, H. (2012). Identity, inequality, and happiness: Evidence from urban China. World Development, 40(6): 1190-1200.

Kahneman, D., and R. Sugden (2005). Experienced utility as a standard of policy evaluation, Environmental and Resource Economics 32(1): 161-181.

Knight, J., Lina, S. O. N. G., and Gunatilaka, R. (2009). Subjective well-being and its determinants in rural China. China Economic Review, 20(4), 635-649.

Knight, J., \& Song, L. (2006). Towards a labour market in China. OUP Catalogue.

Krueger, A. B., and Schkade, D. A. (2008). The reliability of subjective well-being measures. Journal of public economics, 92(8), 1833-1845.

Liang, Y. and P. Lu (2014). Effect of occupational mobility and health status on life satisfaction of Chinese residents of different occupations: logistic diagonal mobility models analysis of cross-sectional data on eight Chinese provinces. International Journal of Equity Health, 13. doi: $10.1186 / 1475-9276-13-15$

Liang, Y., Yi, Y., and Sun, Q. (2014). The impact of migration on fertility under China's underlying restrictions: A comparative study between permanent and temporary migrants. Social Indicators Research, 116(1): 307-326. 
Liang, Y., and Wang, P. (2014). Influence of prudential value on the subjective well-being of Chinese urban-rural residents. Social Indicators Research, 118(3): 1249-1267.

Liang, Y., and Zhu, D. (2014). Subjective Well-Being of Chinese Landless Peasants in Relatively Developed Regions: Measurement Using PANAS and SWLS. Social Indicators Research: 1-19.

Lin, G. and S. Ho, (2003). Emerging Land Markets in Rural and Urban China: Policies and Practices. The China Quarterly, (175): 681-707.

Meng, X. (2012). Labor Market Outcomes and Reforms in China, The Journal of Economic Perspectives, 26(4): 75-101.

Mundlak, Y. (1978). On the pooling of time series and cross section data. Econometrica, 46 (1): 69- 85 .

OECD, (2013). OECD guidelines on measuring subjective wellbeing. Paris: Organisation for Economic Co-operation and Development

OECD (2011) Divided we stand: why inequality keeps rising. Paris: Organisation for Economic Co-operation and Development

Robertson, P. E., and Xu, J. (2008). Education investment in China and its implications for China and East Asia. Researchgate. net, http://www. researchgate. net/publication/255579007_Education_Investment_in_China _and_its_Implications_for_China_and_East_Asia.

Sachs, J. D., Layard, R., and Helliwell, J. F. (2012). World happiness report. The Earth Institute-Columbia University.

Wooldridge, J. M. (2010). Econometric analysis of cross section and panel data. MIT press.

$\mathrm{Wu}, \mathrm{X}$. (2011). The household registration system and rural-urban educational inequality in contemporary China. Chinese Sociological Review, 44(2): 31-51.

Zhang, X. and R. Kanbur (2005). Spatial inequality in education and health care in China, China Economic Review, 33(1):189-204.

Zhao, Z. (2004). Rural-urban migration in China-What do we know and what do we need to know? China Economic Quarterly, 3: 517-536. 
1- When you are doing something, do you find that

(1) Can concentrate; (2) Attention occasionally diverted; (3) Attention sometimes diverted;

(4) Attention frequently diverted, cannot concentrate

2- Do you often lose sleep over worry?

(1) Not at all; (2) Occasionally; (3) Fairly often; (4) Very often

\section{3 - Can you play useful part in things?}

(1) Always can; (2) Can play some positive roles; (3) Can play positive roles poorly;

(4) Cannot play a positive role

4- Are you capable of making decisions?

(1) Always have own opinions; (2) Sometimes have own opinions; (3) Do not have many own opinions; 4) Do not have any personal opinion at all

5- Are you constantly under strain?

(1) Never; (2) Sometimes; (3) Fairly often; (4) Very often

6- Do you feel you couldn't overcome difficulties?

(1) Never; (2) Sometimes; (3) Fairly often; (4) Very often

7- Are you able to enjoy day-to-day activities?

(1) Very interesting; (2) Fairly interesting; (3) Not very interesting;

(4) Not interesting at all

8- Are you able to face problems?

(1) Never; (2) Seldom; (3) Sometimes; (4) Always

9- Do you feel depressed?

(1) Not at all; (2) A little bit; (3) Fairly seriously;

(4) Very seriously

10- Do you always lack confidence?

(1) Not at all; (2) A little bit; (3) Fairly seriously;

(4) Very seriously

11- Do you often think that you have no value?

(1) Not at all; (2) A little bit; (3) Fairly seriously; (4) Very seriously

12- Are you happy when you consider each aspect of your life?

(1) Very happy; (2) Fairly happy; (3) Not very happy; (4) Not happy at all

Source: RUMiC 2008 and 2009. 